\title{
Oestrogen, brain function, and neuropsychiatric disorders
}

\section{W J Cutter, R Norbury, D G M Murphy}

\section{Oestrogen has multiple effects on brain function}

$\square$ here is an increasing amount of research on the neurobiological effects of oestrogen. Also, health professionals are being asked for guidance on whether women should be prescribed oestrogen and progestogen hormone replacement therapy (HRT) not only to treat vasomotor instability and reduce bone loss, but also in various neuropsychiatric disorders. However, it is controversial whether oestrogen is indicated in the treatment of disorders such as depression, Alzheimer's disease, and schizophrenia. A recent large scale study examining the effects of HRT, funded by the National Institutes of Health (NIH) in the USA, was prematurely terminated owing to increased rates of breast cancer heart disease, and stroke. ${ }^{1}$ Shortly afterwards, the WISDOM trial funded by the MRC in the United Kingdom was also terminated. This has reinforced the need to have solid indications for the use of oestrogen-only replacement therapy.

\section{OESTROGEN AS A NEUROPROTECTANT}

Oestrogens affect the development and aging of brain regions that are crucial to higher cognitive functions (like memory) and are implicated in neuropsychiatric disorders such as Alzheimer's disease. For example, oestrogens increase synaptic and dendritic spine density in the hippocampus. In rats, oophrectomy results in a decrease in dendritic spine density in CAl pyramidal cells, but this is prevented by the administration of oestrogens. Moreover, synaptic spine density is related to circulating oestradiol levels. ${ }^{2}$ Until recently it was unclear how these oestrogen induced dendritic changes affected neuronal function. However, it has now been shown that oestrogen induces an increase in N-methyl-D-aspartate (NMDA) receptors in rat hippocampal neurones in the same region where an increase in dendritic spines is found, suggesting that the "new" oestrogen-induced spines are excitatory. ${ }^{34}$

Among the most biologically plausible explanations why HRT might ameliorate age associated deficits in memory are modulatory effects on the cholinergic system in brain regions affected by healthy aging and Alzheimer's disease (for example, the hippocampus and the association neocortex). ${ }^{5}$ The basal forebrain nuclei and hippocampus contain receptors for sex steroids. ${ }^{6}$ Further, in rats oestrogen reverses memory deficits, and ovariectomy decreases cholinergic uptake and choline acetyltransferase activity in the hippocampus and frontal cortex. ${ }^{78}$

There are also indications that oestrogen affects central cholinergic function in healthy female humans. For example oestradiol modulates the growth hormone response to pyridostigmine throughout the menstrual cycle, ${ }^{9}$ and there is a significant correlation between oestradiol levels and cholinergic responsivity. ${ }^{10}$ We recently reported that cholinergic responsivity is greater in women who had received oestrogen replacement therapy than in those who had not. ${ }^{11}$ Moreover, among long term users of oestrogen replacement therapy there was a positive correlation between enhanced cholinergic neurotransmission and longer duration of oestrogen exposure. In contrast, Smith et al found no significant between-group difference in density of the vesicular acetylcholine transporter located in presynaptic terminals (as measured using SPET and the radiotracer $\left.\left[{ }^{123} \mathrm{I}\right] \mathrm{IBVM}\right) .{ }^{12}$ However, they did report a significant relation between length of HRT treatment and synaptic concentration in the frontal, temporal, and parietal cortices. That study was an important first step and suggests that although an overall effect of HRT was not found, it may influence the survival or plasticity of cholinergic cells. Taken together, these findings suggest that in older postmenopausal women oestrogen may be involved in the normal maintenance and physiological regulation of the cholinergic projections, and that oestrogen replacement can enhance the functional status of these cholinergic projections.

Various studies have addressed the relation between oestrogen and the serotonergic (5-hydroxytryptamine, 5-HT) system. The amygdala receives 5-HT projections from the raphé nuclei (at least in the rat $)^{13}$ and oestrogen receptor $\alpha$ mRNA is abundantly expressed in the amygdala $^{14}$ (oestrogen receptors occur in two isoforms, $\alpha$ and $\beta$; both subtypes are expressed in the brain, but with varying patterns of distribution-for a comprehensive review, see Hall et al ${ }^{15}$ ). In rats, the density of $5-\mathrm{HT}_{2 \mathrm{~A}}$ receptors increases during pro-oestrus in the frontal and cingulate cortex. ${ }^{16}$ Similarly, in ovariectomised rats there is an increase in central $5-\mathrm{HT}_{2}$ receptors but a decrease in $5-\mathrm{HT}_{1}$ receptors following oestrogen treatment. ${ }^{17}$ Thus oestrogen can modulate 5-HT receptor density and this may be of relevance to the action of antidepressants and atypical antipsychotics. Oestrogen also increases tryptophan hydroxylase mRNA levels in rhesus macaques $^{18}$ and decreases monoamine oxidase activity in rat brain. ${ }^{6}$ Therefore oestrogen may both encourage the synthesis of 5-HT and decrease its catabolism. In humans, short term oestrogen replacement therapy increases $5-\mathrm{HT}_{2 \mathrm{~A}}$ receptor density, as measured by positron emission tomography (PET). ${ }^{19}$ Also, we showed that oestrogen replacement therapy modulates the age related reduction in serotonergic responsivity in healthy women.$^{20}$ Thus there is increasing evidence that oestrogen interacts with the 5-HT system at multiple levels and this may provide a theoretical role for oestrogen in the regulation of mood.

In addition to direct effects on neurones, oestrogens also act with neurotrophins to stimulate nerve cell growth indirectly. Oestrogen and neurotrophin receptors are co-expressed on rodent neurones in forebrain, hippocampus, and cerebral cortex, and this colocalisation may be important for neuronal survival. ${ }^{21}$ In addition, oestrogen can also protect against neurotoxins that boost free radical production, ${ }^{22}$ it can reduce the neuronal generation of $\beta$ amyloid, $^{23}$ and it can act as an antioxidant. ${ }^{24}$

In summary, there is increasing evidence that oestrogen modulates the aging of brain systems that are both crucial to higher cognitive function and implicated in mood and neuropsychiatric disorders such as Alzheimer's disease.

\section{OESTROGEN AND COGNITIVE FUNCTION}

The most robust effect of oestrogen on cognitive function is most probably on verbal memory. Prospective randomised studies of HRT versus placebo following total abdominal hysterectomy and bilateral salpingo-ophorectomy report a significant positive effect of estrogens on verbal memory. ${ }^{25}{ }^{26}$ Performance in some cognitive tasks also varies as a function of the menstrual cycle in healthy premenopausal women. During the luteal phase (characterised by high levels of oestrogen and progesterone), verbal articulation is improved whereas spatial ability is decreased, ${ }^{27}$ a pattern that is 
reversed during the follicular phase (when there is relatively low oestrogen and progesterone). A similar pattern of cognitive performance is also observed if subjects are tested during the preovulatory oestradiol surge (to control for the potential effects of progesterone on cognitive performance), suggesting that oestrogen rather than progesterone is responsible for the observed cognitive effects.

Functional imaging techniques have also been employed to assess the effects of oestrogen on networks subserving various aspects of cognitive function (see Maki and $\operatorname{Resnick}^{28}$ for a review). A recent randomised, placebo controlled crossover study using functional magnetic resonance imaging ${ }^{29}$ found oestrogen induced alterations in brain activation patterns during encoding and retrieval of both verbal and non-verbal stimuli. More recently, Maki and Resnick ${ }^{30}$ used PET and ${ }^{15} \mathrm{O}$ to examine longitudinal changes in regional cerebral blood flow (rCBF) over a two year interval in women on and off HRT (both with and without adjuvant progesterone therapy). Significant differences in $\mathrm{rCBF}$ were found in the right hippocampus, the parahippocampal gyrus, and the left middle temporal gyrus-regions crucial to memory. We recently reported that oestrogen reduces age related differences in neuronal membrane breakdown (as measured by ${ }^{1} \mathrm{H}$ magnetic resonance spectroscopy) in the hippocampus and parietal lobe, and this was related to memory function. ${ }^{31}$

Thus there is increasing evidence from in vivo brain imaging studies that estrogen modulates cognitive function, cerebral blood flow, and membrane breakdown. However, further prospective randomised studies are required.

\section{OESTROGEN AND ALZHEIMER'S DISEASE}

Epidemiological studies have reported that the prevalence of Alzheimer's disease is significantly decreased in women on HRT, and that those women with Alzheimer's disease who were taking HRT had milder disease than those who were not. ${ }^{32}$ A recent longitudinal study reported that prolonged use of HRT decreased the risk and delayed the onset of Alzheimer's disease (relative risk $=0.40 ; 95 \%$ confidence interval, 0.22 to 0.85 ); moreover, the use of oestrogen for longer than one year reduced the risk of developing Alzheimer's disease by 5\%. ${ }^{33}$ However, results from such studies are often difficult to interpret. For example, women who use oestrogen are often better educated, generally healthier, and less depressed than non-users-a factor known as "the healthy user bias". Thus we cannot exclude the possibility that oestrogen use reflects an as yet unidentified bias that accounts for the effects observed..$^{33}$

Results from early clinical trials of HRT in people with Alzheimer's disease suggested that it may also benefit women with established disease. For example, women with Alzheimer's disease who were using oestrogen had better scores on the Alzheimer's disease assessment scale (ADAS-Cog, a standard instrument used in clinical trials on Alzheimer's disease) than their counterparts who did not take oestrogens. ${ }^{34}$ However, results from recent large randomised double blind, placebo controlled trials are less optimistic. ${ }^{35-37}$ These studies reported no beneficial effects of HRT on cognition, mood, or functional outcomes in Alzheimer's disease. In contrast, a smaller study by Asthana et al reported a significant treatment benefit after a four week treatment period with oestradiol patches in subjects with Alzheimer's disease. ${ }^{38}$ However, the effects were temporary and diminished once treatment ceased. The differences in results may be explained by differences in the type of HRT used (Asthana used an oestradiol patch, whereas Mulnard et al employed oral conjugated equine oestrogen (CEE) in 120 hysterectomised women with mild to moderate Alzheimer's disease for a period of one year $\left.{ }^{39}\right)$. A significant improvement on the mini-mental state examination was also reported by Mulnard after two months' treatment with CEE. However, the benefit did not persist with prolonged treatment. Overall, oestrogen replacement therapy for one year did not slow disease progression or improve cognitive function.

Thus current evidence does not support a role for oestrogen in the treatment of established Alzheimer's disease. However, oestrogen may be a neuroprotectant in healthy brain and delay the onset of Alzheimer's disease. Perhaps in the established disease the potential therapeutic window has been missed and the remaining neurones are refractory to the beneficial effects of oestrogen, although oestrogen may still be useful as an augmentation strategy in those taking acetylcholinesterase inhibitors. ${ }^{40}$

\section{OESTROGEN AND \\ SCHIZOPHRENIA}

There are sex differences in premorbid functioning, age of onset, symptomatology, and outcome of schizophrenia. For example, men have a single peak of disease onset in their early twenties, whereas women have a later age of onset and a second peak in incidence between the ages of 45 and 55 years. In addition, women are more likely to have a family history of schizophrenia, display atypical or affective features, and have a seasonal pattern of hospital admission. Because oestrogen has putative antidopaminergic/ antipsychotic actions, it has been suggested that in women oestrogens may be responsible for the delayed onset of the first schizophrenia peak, and that the second peak may reflect the decline in oestrogen levels at the menopause. There is evidence that oestrogen protects the nigrostriatal dopaminergic system against the neurotoxic effects of MPTP in rats. ${ }^{41-43}$ An antipsychotic action of oestrogens is supported by clinical studies reporting that women have increased admission rates for psychosis around the menses $^{42}$ and that psychotic symptomatology varies with phase of the menstrual cycle. ${ }^{43} 44$ Also, women with schizophrenia may have reduced oestradiol concentrations compared with controls. ${ }^{44}$ However, there is currently little evidence to support the therapeutic use of oestrogen in schizophrenia. For example, when women with schizophrenia are treated with adjunctive oestrogen there is a slight increase in speed of recovery, but no improvement overall as compared with antipsychotic drug treatment alone. ${ }^{45}$ Despite the lack of clear evidence for the efficacy of oestrogen as an antipsychotic agent, it remains plausible that oestrogen replacement therapy might protect against late onset schizophrenia in postmenopausal women by reducing age related changes in brain structure and neurochemistry (for example, in the hippocampus).

\section{OESTROGEN AND DEPRESSION}

Epidemiological studies suggest that, in addition to psychosocial factors, times of change in oestrogen levels make depression more likely in a vulnerable subgroup of women. For example, after puberty, women are around twice as likely to suffer depression than men $^{46}$ and in the postpartum period there is a peak of incidence. ${ }^{47}$ However, although the perimenopausal period brings with it an increase in mild depressive symptoms, there is no increase in depressive disorders $^{46}$ and there is evidence that the prevalence of depression decreases postmenopausally. ${ }^{48}$

In the light of the above findings, it has been suggested that oestrogen may have a role as an antidepressant. However, methodological difficulties affect the few studies in this area. These include small numbers of subjects, the lack of control groups, and (in the studies of menopausal depression) a variable or inadequate definition of the menopause and the use of multiple HRT preparations. In postpartum depression, oestrogen therapy may be useful both as prophylaxis in vulnerable individuals ${ }^{49}$ and as a treatment. ${ }^{50}$ In high doses, 
oestrogen has been reported as being useful in non-postpartum treatment of resistant depression in women, ${ }^{51}$ but this small study has yet to be replicated. There is also some evidence that women taking oestrogen replacement therapy may respond better to fluoxetine. ${ }^{52}$ In the perimenopause,oestrogen replacement therapy is effective in reducing mild depressive symptoms ${ }^{46}$ and it has been reported to be an effective treatment for depression. ${ }^{53}{ }^{54}$ However, it is difficult to determine from these studies whether the oestrogen is treating menopausal symptoms such as sleep deprivation and anergia or the depression per se.

Currently, there is little evidence to suggest that oestrogen is a useful treatment for depression during the menopause or at other times. Indeed it is our opinion that oestrogen replacement or HRT should not be used as a first line treatment for depression in any group of depressed women, although in nondepressed individuals it can foster a sense of "psychological wellbeing" in the perimenopausal period ${ }^{46}$ Oestrogen may, however, have a role as a time limited (brief) adjunct to antidepressants in treatment resistant depression, or in the alleviation of mild mood symptoms (which are nonetheless distressing) in peri-postmenopausal women.

\section{CONCLUSIONS}

Basic research indicates that oestrogen has multiple effects on brain function, modulating aspects of neurotransmitter function, glucose metabolism, synaptogenesis, and brain aging. In line with this, epidemiological studies implicate oestrogen in the aetiology of neuropsychiatric disorders. However, these encouraging findings do not at present translate into the use of oestrogen as a treatment. Current evidence suggests that oestrogen alone has no role in the treatment of established Alzheimer's disease, but may delay its onset. The evidence base for the use of oestrogen as an adjunct to neuroleptics in schizophrenia or in the treatment of postnatal and perimenopausal depression is currently too weak to merit a change in clinical practice. Larger prospective studies are required to establish whether oestrogen has a role in the prophylaxis and treatment of these disorders.

J Neurol Neurosurg Psychiatry 2003;74:837-840

\section{Authors' affiliations \\ W J Cutter, R Norbury, D G M Murphy,}

Division of Psychological Medicine, Box P050, Institute of Psychiatry, De Crespigny Park, London SE5 8AF, UK

Correspondence to: R Norbury; sppmran@iop.kcl.ac.uk

\section{REFERENCES}

Writing group for the Women's Health Initiative. Risks and benefits of oestrogen plus progestin in healthy postmenopausal women. JAMA 2002;288:32 1-33.

2 Gould E, Woolley CS, Frankfurt M, et al. Gonadal steroids regulate dendritic spine density in hippocampal pyramidal cells in adulthood. J Neurosci 1990;10:1286-91.

3 Gazzaley AH, Weiland NG, McEwen BS, et al. Differential regulations of NMDAR 1 mRNA and protein by estradiol in the rat hippocampus. J Neurosci 1996;16:6830-8.

4 Woolley CS, Weiland NG, McEwen BS, et al. Estradiol increases the sensitivity of hippocampal CA1 pyramidal cells to NMDA receptor-mediated synaptic input: correlation with dendritic spine density. $J$ Neurosci 1997: 17: 1848-59.

5 McEwen BS, Alves SE, Bulloch K, et al. Ovarian steroids and the brain: implications for cognition and aging. Neurology 1997;48(suppl 7):S8-15.

6 Luine VN, Khylchevskaya RI, McEwen BS Effect of gonadal steroids on activities of monoamine oxidase and choline acetylase in rat brain. Brain Res 1975;86:293-306.

7 Singh M, Meyer EM, Millard WJ, et al. Ovarian steroid deprivation results in a reversible learning impairment and compromised cholinergic function in female Sprague-Dawley rats. Brain Res 1994;644:305-12

8 Gibbs RB, Burke AM, Johnson DA. Estrogen replacement attenuates effects of scopolamine and lorazepam on memory acquisition and retention. Hormones Behav 1998;34:112-25.

9 O'Keane V, Dinan TG. Sex steroid priming effects on growth hormone response to pyridostigmine throughout the menstrual cycle. J Clin Endocrinol Metab 1992;75:11-14.

10 Lucey JV, O'Keane V, O'Flynn K, et al. Gender and age differences in the growth hormone response to pyridostigmine. Int Clin Psychopharmacol 1991;6:105-9.

11 Van Amelsvoort T, Murphy DGM, Robertson $D$, et al. Effects of long-term estrogen replacement therapy on growth hormone response to pyridostigmine in healthy postmenopausal women.

Psychoneuroendocrinology 2003;28:101-12.

12 Smith YR, Minoshima S, Kuhl DE, et al. Effects of long-term hormone therapy on cholinergic synaptic concentrations in healthy postmenopausal women. J Clin Endocrinol Metab 2001;86:679-84.

13 Vertes RP. A PHA-L analysis of ascending projections of the dorsal raphe nucleus in the rat. J Comp Neurol 1991;313:643-68.

14 Osterlund MK, Keller E, Hurd YL. The human forebrain has discrete estrogen receptor alpha messenger RNA expression: high levels in the amygdaloid complex. Neuroscience 2000;95:333-42.

15 Hall JM, Couse JF, Korach KS. The multifaceted mechanisms of estradiol and estrogen receptor signaling. J Biol Chem 2001;276:36869-72.

16 Sumner BE, Fink G. The density of 5 -hydoxytryptamine2A receptors in forebrain is increased at pro-oestrus in intact female rats. Neurosci Lett 1997;234:7-10.

17 Biegon A, Reches A, Snyder L, et al. Serotonergic and noradrenergic receptors in the rat brain: modulation by chronic exposure to ovarian hormones. Life $\mathrm{Sci}$ 1983;32:2015-21.

18 Pecins-Thompson $M$, Brown NA, Kohama $S G$, et al. Ovarian steroid regulation of tryptophan hydroxylase mRNA expression in rhesus macaques. J Neurosci 1996;16:7021-9.

19 Moses EL, Drevets WC, Smith G, et al. Effects of estradiol and progesterone administration on human serotonin 2A receptor binding: a PET study. Biol Psychiatry 2000;48:854-60.

20 van Amelsvoort T, Abel KM, Robertson DM, et al. Prolactin response to d-fenfluramine in postmenopausal women on and off ERT: comparison with young women.

Psychoneuroendocrinology 2001;26:493-502.
21 Toran-Allerand CD. The estrogen/ neurotrophin connection during neural development: is co-localization of estrogen receptor with the neurotrophins and their receptors biologically relevant? Dev Neurosci 1996; 18:36.

22 Simpkins JW, Singh M, Bishop J. The potential role for estrogen replacement therapy in the treatment of the cognitive decline and neurodegeneration associated with Alzheimer's disease. Neurobiol Aging 1994;15(suppl 2):S195-7.

23 Xu H, Gouras GK, Greenfield JP, et al. Estrogen reduces neuronal generation of Alzheimer beta-amyloid peptides. Nat Med 1998:4:447-51

24 Behl C. Oestrogen as a neuroprotective hormone. Nat Rev Neurosci 2002;3:433-42.

25 Sherwin BB. Estrogen and/or androgen replacement therapy and cognitive functioning in surgically menopausal women. Psychoneuroendocrinology 1988;13:345-57.

26 Phillips SM, Sherwin BB. Effects of estrogen on memory function in surgically menopausal women. Psychoneuroendocrinology 1992;17:485-95.

27 Hampson E. Variations in sex-related cognitive abilities across the menstrual cycle. Brain Cogn 1990;14:26-43.

28 Maki PM, Resnick SM. Effects of estrogen on patterns of brain activity at rest and during cognitive activity: a review of neuroimaging studies. Neuroimage 2001;14:789-801.

29 Shaywitz SE, Shaywitz BA, Pugh KR, et al. Effect of estrogen on brain activation patterns in postmenopausal women during working memory tasks. JAMA 1999;281:1197-202.

30 Maki PM, Resnick SM. Longitudinal effects of estrogen replacement therapy on PET cerebral blood flow and cognition. Neurobiol Aging 2000;21:373-83.

31 Robertson DM, van Amelsvoort T, Daly E, et al. Effects of estrogen replacement therapy on human brain aging: an in vivo $1 \mathrm{H}$ MRS study. Neurology 2001;57:2114-17.

32 Henderson VW, Paganini-Hill A, Emanuel CK, et al. Estrogen replacement therapy in older women: comparisons between Alzheimer's disease cases and nondemented control subjects. Arch Neurol 1994;51:896-900.

33 Tang MX, Jacobs D, Stern Y, et al. Effect of oestrogen during menopause on risk and age at onset of Alzheimer's disease. Lancet 1996;348:429-32.

34 Doraiswamy PM, Krishen A, Martin WL, et al. Gender, concurrent estrogen use and cognition in Alzheimer's disease. Int J Geriatr Psychopharmacol 1997;1:34-7.

35 Wang PN, Liao SQ, Liu RS, et al. Effects of estrogen on cognition, mood, and cerebral blood flow in AD: a controlled study. Neurology 2000;54:2061-6

36 Henderson VW, Paganini-Hill A, Miller BL, et al. Estrogen for Alzheimer's disease in women: randomized, double-blind placebo-controlled trial. Neurology 2000;54:295-301

37 Mulnard RA, Cotman CW, Kawas C, et al. Estrogen replacement therapy for treatment of mild to moderate Alzheimer disease: a randomized controlled trial. Alzheimer's Disease Cooperative Study. JAMA 2000;283: 1007-15

38 Asthana S, Baker LD, Craft S, et al. High-dose estradiol improves cognition for women with AD: results of a randomized study. Neurology 2001;57:605-12.

39 Mulnard RA, Cotman CW, Kawas C, et al. Estrogen replacement therapy for treatment of mild to moderate Alzheimer disease: a randomized controlled trial. JAMA 2000;283: 1007-15.

40 Schneider LS, Farlow MR, Henderson VW, et al. Effects of estrogen replacement therapy on response to tacrine in patients with

Alzheimer's disease. Neurology 1996;46: 1580-4.

41 Dluzen DE, McDermott JL, Liu B. Estrogen alters MPTP-induced neurotoxicity in female mice: effects on striatal dopamine concentrations and release. J Neurochem 1996;66:658-66. 


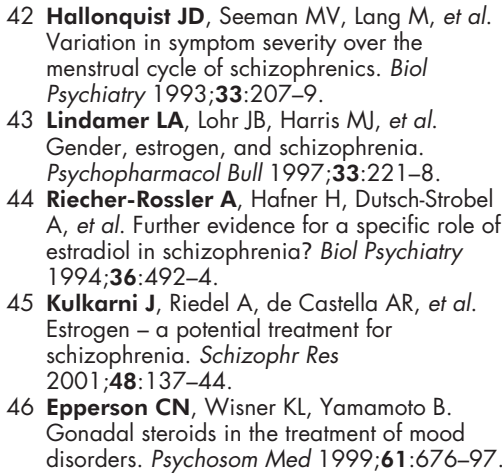

42 Hallonquist JD, Seeman MV, Lang M, et al. Variation in symptom severity over the menstrual cycle of schizophrenics. Biol Psychiatry 1993;33:207-9.

43 Lindamer LA, Lohr JB, Harris M, et al. Gender, estrogen, and schizophrenia. Psychopharmacol Bull 1997;33:221-8.

44 Riecher-Rossler A, Hafner H, Dutsch-Strobel $A$, et al. Further evidence for a specific role of estradiol in schizophrenia? Biol Psychiatry 1994;36:492-4.

45 Kulkarni J, Riedel A, de Castella AR, et al. Estrogen - a potential treatment for schizophrenia. Schizophr Res 2001;48:137-44.

46 Epperson CN, Wisner KL, Yamamoto B. Gonadal steroids in the treatment of mood disorders. Psychosom Med 1999;61:676-97.

47 Kumar R, Robson KM. A prospective study of emotional disorders in childbearing women. Br J Psychiatry 1984;144:35-47.

48 Bebbington PE, Dunn G, Jenkins R, et al. The influence of age and sex on the prevalence of depressive conditions: report from the National Survey of Psychiatric Morbidity. Psychol Med 1998;28:9-19.

49 Sichel DA, Cohen LS, Robertson LM, et al. Prophylactic estrogen in recurrent postpartum affective disorder. Biol Psychiatry 1995;38:814-18.

50 Gregoire AJP, Kumar R, Everitt B, et al. Transdermal oestrogen for treatment of severe postnatal depression. Lancet 1996:347:930-3.

51 Klaiber EL, Broverman DM, Vogel W, et al. Estrogen therapy for severe persistent depressions in women. Arch Gen Psychiatry 1979;36:550-4.

52 Schneider LS, Small GW, Hamilton SH, et al. Estrogen replacement and response to fluoxetine in a multicenter geriatric depression trial. Fluoxetine Collaborative Study Group. Am J Geriatr Psychiatry 1997;5:97-106.

53 Schmidt PJ, Nieman L, Danaceau MA, et al. Estrogen replacement in

perimenopause-related depression: a preliminary report. Am J Obstet Gynecol 2000; 183:414-20.

54 Soares CN, Almeida OP, Joffe H, et al. Efficacy of estradiol for the treatment of depressive disorders in perimenopausal women: a double-blind, randomized, placebo-controlled trial. Arch Gen Psychiatry 2001;58:529-34. signal abnormalities after intra-arterial thrombolysis, which correlated to improved clinical outcome in several cases. ${ }^{10}$ Animal studies in models of ischaemia and reperfusion have shown the delayed recurrence of DWI lesions after initial normalisation, which correlated to histologic indicators of neuronal damage. ${ }^{11}$ DWI is a composite of the apparent diffusion coefficient (ADC) and T2 weighting. Pseudonormalisation of DWI may be an artifact of the varying impact of these two components. ${ }^{11}$ ADC values in rats after middle cerebral artery occlusion and reperfusion have also been shown to normalise and secondarily become abnormal with underlying histologic evidence of ischaemic damage, but with no worse functional outcome (similar to the fate of the human subjects in the initial Kidwell study). ${ }^{12}$ Subsequently Kidwell's group showed MRI confirmation of these basic studies with the DWI abnormalities either remaining, normalising, or secondarily becoming abnormal. ${ }^{13}$ Further studies delineating the significance of MRI and molecular changes following ischaemia, and what clinical impact these changes have, will lead to a greater understanding of their significance and potentially new criteria to determine best stroke therapy.

As these new MR techniques are being applied to acute stroke, the very definition of TIA is again under fire. In this study, the authors rely on a clinical definition of stroke when it was at odds with the DWI evidence for cerebral injury. Others have suggested a new definition of TIA that would take into account all information available, including advanced imaging methods, and exclude episodes that had evidence for ischaemic injury and refer to them as a stroke. ${ }^{14}$

By showing a method that may reliably predict a diffusion/perfusion mismatch in a subset of patients, the authors have helped us on our progress 
away from a strictly time based criteria for reperfusion and neuroprotective therapies. Further studies with larger numbers should be performed to confirm these results. Future studies using combined standardised clinical and imaging assessments as well as further studies using a combination of molecular, cellular, and MRI imaging should help to determine the physiological and functional relevance of DWI/ PWI mismatch and the ischaemic penumbra.

J Neurol Neurosurg Psychiatry 2003;74:840-841

\section{Authors' affiliations}

D M Brown, S R Levine, Stroke Program, Department of Neurology, The Mount Sinai School of Medicine, New York, NY

10029-6574, USA

Correspondence to: S R Levine, Stroke Program, Department of Neurology, Box 1137, The Mount Sinai School of Medicine, One Gustave L. Levy Place, New York, NY 10029-6574,

USA; steven.levine@mssm.edu

\section{REFERENCES}

1 The National Institute of Neurological Disorders and Stroke rt-PA Stroke Study Group. Tissue plasminogen activator for acute ischemic stroke. N Engl J Med ischemic stroke. N EnglJ

2 Marler JR, Tilley BC, Lu M, et al. Early stroke treatment associated with better outcome: the NINDS rt-PA stroke study. Neurology 2000;55(1 1): 1649-55.

3 Overgaard K, Sereghy T, Pedersen $\mathrm{H}$, et al. Effect of delayed thrombolysis with rt-PA in a rat embolic stroke model. J Cereb Blood Flow Metab 1994;14(3):472-7.

4 Ernst R, Pancioli A, Tomsick $T$, et al. Combined intravenous and intra-arterial recombinant tissue plasminogen activator in acute ischemic stroke. Stroke 2000:31(11):2552-7.

5 Mansbach H, D'Olhaberriague L, Nagesh V, et al. Tissue-based rather than time-based strategies for thrombolysis in acute stroke. Neurology 1996;46(Suppl 1):A256.

6 Schellinger PD, Fiebach JB, Hacke W. Imaging-based decision making in thrombolytic therapy for ischemic stroke: present status. Stroke 2003;34(2): 575-83.

7 Alder SJ, Moody A, Martel A, et al. Differences in the diagnostic accuracy of acute stroke clinical subtypes defined by multimodal magnetic resonance imaging. $J$ Neurol Neurosci Psychiatry 2003;74 886-8.
8 Barber PA, Davis SM, Darby DG, et al. Absent middle cerebral artery flow predicts the presence and evolution of the ischemic penumbra. Neurology 1999;52(6): 1125-32.

9 Muir KW, Grosset DG. Neuroprotection for acute stroke: making clinical trials work. Stroke 1999;30(1):180-2

10 Kidwell CS, Saver JL, Mattiello J, et al. Thrombolytic reversal of acute human cerebral ischemic injury shown by diffusion/perfusion magnetic resonance imaging. Ann Neurol 2000:47(4):462-9

11 Neumann-Haefelin T, Kastrup A, de Crespigny $A$, et al. Serial MRI after transient focal cerebral ischemia in rats: dynamics of tissue injury, blood-brain barrier damage, and edema formation. Stroke 2000;31(8):196572.

12 Li F, Silva MD, Liu KF, et al. Secondary decline in apparent diffusion coefficient and neurological outcomes after a short period of focal brain ischemia in rats. Ann Neurol 2000;48(2):236-44

13 Kidwell CS, Saver JL, Starkman S, et al. Late secondary ischemic injury in patients receiving intraarterial thrombolysis. Ann Neurol 2002;52(6):698-703.

14 Albers GW, Caplan LR, Easton JD, et al. Transient ischemic attack-proposal for a new definition. N Engl J Med, 2002;347(21):1713-6

\section{Head injury and Alzheimer's disease}

\section{J T L Wilson}

\section{Update on the link between head injury and Alzheimer's disease}

$\mathrm{n}$ this issue (see pp 857-862) Fleminger and colleagues ${ }^{1}$ provide a timely update on the status of the link between head injury and Alzheimer's disease. Forty three case-control studies are identified in their review, and 15 met strict methodological criteria for inclusion in the overall meta-analysis. The balance of evidence, at least in males, is now firmly for the existence of an association.

The issue is important both theoretically and in clinical practice. Clinicians are increasingly called on to give advice on the link between head injury and Alzheimer's disease. Should advice about the increased risk of developing Alzheimer's disease be given routinely to head injured people? Advice might encourage the person to avoid the risk of further injury and aid them in seeking help early if symptoms of the disease became apparent. Clinical opinion is also sometimes sought on whether previous head injury is a major contributing cause in those who develop Alzheimer's disease. In a landmark case in November 2002, a coroner's court in Burton-upon-Trent recorded a verdict of death by industrial disease in the case of Jeff Astle. This former England footballer had died at the age of 59 after having developed Alzheimer's disease. In this case neuropathological evidence of brain injury that was apparently caused by heading the ball was of key importance in the decision concerning the cause of death.

The epidemiological studies reviewed by Fleminger et al suffer from inherent weaknesses. Crucially, all the studies described rely on the report of an informant to ascertain whether a head injury causing loss of consciousness had occurred in the lifetime of the individual. Recall bias and inaccuracy are thus major limitations. In these studies it is impossible to establish reliably the nature and severity of the original injury. Such uncertainty may account for some of the inconsistencies in published reports. The difference between men and women, for example, may arise because men have typically had more severe injuries.

More generally the case-control approach is too imprecise to answer questions remaining concerning the link. For example, does severity of head injury affect the likelihood of developing the Alzheimer's disease, and does this interact with genotype? ${ }^{2}$ Does repetitive head injury lead to earlier onset? ${ }^{3}$ It is to be hoped that this review by Fleminger et al will help stimulate the follow up of cohorts of patients with well documented head injuries. The emphasis should now be on understanding the link better rather than on documenting its existence.

J Neurol Neurosurg Psychiatry 2003;74:841

\section{Author's affiliation}

J T L Wilson, Department of Psychology, Cottrell Building, University of Stirling, Stirling FK9 4LA, UK; j.t.I.wilson@stir.ac.uk

\section{REFERENCES}

1 Fleminger S, Oliver, DL, Lovestone S, et al. Head injury as a risk factor for Alzheimer's disease; the evidence ten years on. A partial replication. J Neurol Neurosurg Psychiatry 2003;74:857-62.

2 Plassman BL, Havlik RJ, Steffens DC, et al. Documented head injury in early adulthood and risk of Alzheimer's disease and other dementias. Neurology 2000;55: 1158-66.

3 Uryu K, Laurer H, Mclntosh T, et al. Repetitive mild brain trauma accelerates $A$ beta deposition, lipid peroxidation, and cognitive impairment in a transgenic mouse model of Alzheimer amyloidosis. J Neurosci 2002;22:446-54. 


\section{Surgery for chronic subdural haematoma: is there an evidence base?}

\section{T Dunn}

It is time for a well designed and adequately sized clinical trial of the treatment of chronic subdural haematoma

n their paper on pp 937-943 (this issue), ${ }^{1}$ Weigel et al have assessed in a systematic way the published studies on outcome following different surgical treatments for chronic subdural haematoma. They suggest that burr hole evacuation has the best cure/ complication ratio and that postoperative closed system drainage reduces the risk of recurrence. One of their striking findings is the small number of good quality studies published on this topic. There are no randomised controlled trials to provide class I evidence, and only six studies that provide class II evidence. This limits the strength of the recommendations that can be made and precludes application of the statistical techniques of meta-analysis. Given that chronic subdural haematoma is a common condition in routine neurosurgical practice, this paucity of good quality clinical studies seems surprising. There are real and recognised, but not insurmountable, difficulties in conducting randomised controlled trials in surgery. ${ }^{23}$ They are expensive, difficult to set up, and difficult to conduct. Surgeons often have strongly held opinions about the "best" treatment in a given situation and it can be difficult to convince them of the need for or value of clinical trials of established treatments. On the other hand the mortality and morbidity reported in the various studies cited in
Weigel's paper vary widely-mortality between $0 \%$ and $11 \%$, morbidity between $0 \%$ and $25 \%$, and recurrence between $0 \%$ and $76 \%$. Much of this variability almost certainly relates to baseline differences in the various patient groups but some is likely to relate to the different treatment methods. The best way to resolve these issues would be with a well designed and adequately sized clinical trial and perhaps the time has come to consider doing this, so that we can provide our patients with a rational basis for the treatment(s) we offer for this common condition.

J Neurol Neurosurg Psychiatry 2003;74:842

\section{Author's affiliation}

L T Dunn, Department of Neurosurgery, Glasgow University, Southern General Hospital, Glasgow G51 4TF, UK; Itd 1x@udcf.gla.ac.uk

\section{REFERENCES}

1 Weigel R, Schmiedek P, Krauss JK. Outcome of contemporary surgery for chronic subdura haematoma: evidence based review. I Neurol Neurosurg Psychiatry 2003;74:937-43.

2 Baum M. Reflections on randomised controlled trials in surgery. Lancet 1999;353(suppl 1):6-8.

3 Haines SJ. Randomized clinical trials in neurosurgery. Neurosurgery 1983;12: 259-64

\section{The outcome of depressive disorders in the setting of neurological illness}

\section{H Rickards}

\section{Depression is a common and disabling feature in neurological outpatients}

\footnotetext{
7 he depressions are a heterogeneous group of conditions. This is particularly true when depressive symptoms are experienced in the setting of coarse brain disease. Here the clinical presentation, differential diagnosis, and aetiology offer unique challenges to the clinician. The development of broader, more patient centred outcome measures such as quality of life and "health gain" has also elevated the status of depression, particularly because depressive symptoms are now seen to be the primary contributors to morbidity in some neurological illnesses. Two recent
}

studies showed how depressive symptoms accounted for much more of the variance in morbidity in Parkinson's disease $(40 \%)$ than did movement disorder $(17 \%) .{ }^{12}$ Critics of these studies could rightly point out that before the advent of L-dopa, motor disorder was definitely the biggest contributor to morbidity in Parkinson's disease, and that quality of life as a measure is more directly related to mood state in its broadest sense. Nevertheless, a more neuropsychiatric model of brain disease has developed, where cognitive and affective symptoms are seen in the same light as motor or somatic symptoms.
There are several factors that affect outcome in depression in the setting of neurological illness. First there is a question of whether the depression is being recognised. Most studies of patients within neurological clinics suggest that is it not. The next question is whether or not treatments for depression are effective in the setting of neurological illness. The answer to this question depends on which neurological condition is in consideration. The plethora of small case series in different neurological disorders suggests that antidepressants and cognitive behaviour therapy are effective (as both are clearly proven to be in "idiopathic" depression) but there is a dearth of randomised controlled trials in this area. The most notable is the lack of treatment trials for depression in the setting of Parkinson's disease. Finally, neurological illnesses greatly differ in their course, outcome, and tendency to produce disability, all of which could directly affect the course and prognosis of any co-morbid affective disorder. To use the example of multiple sclerosis, Chwastiak et al looked at depressive symptoms in a community sample of people with multiple sclerosis and found two groups who were more at risk of 
depression-those early in the course of illness and those with severe physical disability. ${ }^{3}$

The data from the study by Carson et al (see pp 893-896, this issue) show that depressive illness is common in neurological outpatients $(40 \%$ with major depressive disorder) and that the incidence over the study period was also high (with 20 new cases, of a total of 226 , arising during the study period of eight months). ${ }^{4}$ The majority of the people with depression initially were still depressed at the end of the study. Recovery from depression in the study period was associated strongly with "health gain" (measured by the SF-36), but this was independent of physical status, although the numbers were small. The study does not address the issue of whether depression was recognised or treated adequately during the study period, and this would be a suitable subject for further investigation.

In another study from the same centre (see pp 897-900, this issue), ${ }^{5}$ depression is related to the presence of medically unexplained neurological symptoms. An eight month prospective study of this group of patients showed an increased rate of depression and anxiety compared with patients with clear "organic" disorders at baseline. Physical recovery at eight months was accompanied by comparable improvement in mental health.
What lessons can be learned so far? Depression is a common and disabling feature in neurological outpatients, and neurological clinicians should give greater prominence to its diagnosis and management. Brain disorders should be seen from a more neuropsychiatric perspective, with cognition and affect considered on a par with motor and other somatic domains. These lessons add weight to the argument for more integrated training in brain disorders, with neurological trainees in particular having tuition in the recognition and treatment of abnormal mental states in the setting of neurological illness (possibly in exchange for training psychiatrists in neurological examination and diagnosis).

Treatment trials are definitely needed to assess the efficacy of pharmacotherapy and psychological treatments (particularly cognitive behavioural therapy, which has a place in the management of patients who are already on multiple drug treatment or who would find antidepressants difficult to tolerate).

Finally, further studies could continue to address depression in specific neurological disorders, looking at phenomenology, illness course, and treatment response. Studies of depression in a neurology clinic setting could be done as an audit of clinical practice, to ascertain whether or not clinicians were recognising and treating depression effectively. J Neurol Neurosurg Psychiatry
2003;74:842-843

\section{Author's affiliation}

H Rickards, Department on Neuropsychiatry, Queen Elizabeth Psychiatric Hospital, Mindelsohn Way, Edgbaston, Birmingham B15 2QZ, UK;

hugh.rickards@sbmht.wmids.nhs.uk

\section{REFERENCES}

1 Schrag A, Jahanshahi M, Quinn N. What contributes to quality of life in patients with Parkinson's disease? J Neurol Neurosurg Psychiatry 2000;69:308-12.

2 Karlsen KH, Larsen JP, Tanberg E, et al. Influence of clinical and demographic variables on quality of life in patients with Parkinson's disease. J Neurol Neurosurg Psychiatry 1999;66:431-5.

3 Chwastiak L, Ehde DM, Gibbons LE, et al. Depressive symptoms and severity of illness in multiple sclerosis: epidemiologic study of a large community sample. Am J Psychiatry 2002;159:1862-8

4 Carson AJ, Postma K, Stone J, et al. The outcome of depressive disorders in neurology outpatients: a prospective cohort study. J Neurol Neurosurg Psychiatry 2003;73:893-6.

5 Carson AJ, Best B, Postma K, et al. The outcome of neurology outpatients with medically unexplained symptoms: a prospective cohort study. J Neurol Neurosurg Psychiatry 2003;73:897-900.

NEUROLOGICAL STAMP

Otto Loewi (1873-1961)

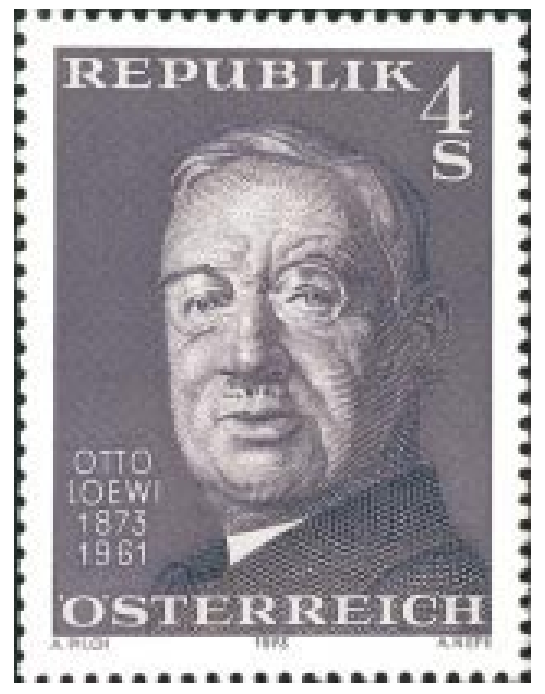

O tto Loewi, the son of a wine merchant, was born in Frankfurt-am-Main. As a young man he wished to study art history but, persuaded by his parents, he studied medicine at the Universities of Strasbourg and Munich. Loewi held professorships in physiology and pharmacology at Vienna and Graz Universities (1909-1938). Before graduation he conducted pharmacological research into the effects of drugs on the isolated heart of the frog. Later, dispirited by clinical work in a tuberculosis ward he returned to research with the eminent pharmacologist HH Meyer in Marburg. None of his early work was directly concerned with chemical neurotransmission, for which he later received the Nobel Prize. Between 1921 and 1926 Otto Loewi and his coworkers showed that stimulation of the parasympathetic nerves in a perfused frogs heart resulted in the appearance of a substance that inhibited the action of a second heart receiving the perfused fluid from the first heart. Similar stimulation of the sympathetic nerves of the first heart promoted its beating. Again transfer of the perfused solution induced the same changes in the second heart. His later work on establishing the identities of the vagus transmitter (vagusstoff) and the sympathetic transmitter (acceleranstoff) provided convincing evidence of chemical mediation of nerve impulses. In 1926 Loewi and his collaborator E Navratil suggested that vagusstoff was acetylcholine. In 1929 Henry Dale and Harold Dudley isolated acetylcholine from animal tissue. Otto Loewi and Henry Dale shared the Nobel Prize for physiology or medicine in 1936. Work on identifying acceleranstoff proceeded more slowly. Loewi left Austria after the Nazi invasion in 1938, but his wife was detained in Austria until his family assets, including his Nobel Prize money, had been transferred to Nazi banks. He eventually settled in the US. In 1940 he accepted a research professorship at the New York University school of medicine and in 1946 became an American citizen. In 1973, the centenary of his birth, Austria honoured him on a stamp (Stanley Gibbons no 1659, Scott no 942).

L F Haas 